\title{
Preface: Advances in hydrogeologic understanding of Australia's Great Artesian Basin
}

\author{
Carlos Miraldo Ordens ${ }^{1} \cdot$ Neil Mclntyre ${ }^{1} \cdot \operatorname{Jim}$ R. Underschultz ${ }^{2} \cdot$ Tim Ransley $^{3} \cdot$ Catherine Moore $^{4} \cdot$ Dirk Mallants $^{5}$
}

Received: 16 December 2019 / Accepted: 21 December 2019/Published online: 22 January 2020

(C) Springer-Verlag GmbH Germany, part of Springer Nature 2020

\section{Introduction}

Australia's Great Artesian Basin (GAB) is one of the world's most iconic and largest groundwater basins, covering over 1.7 million $\mathrm{km}^{2}$ ( $\sim 22 \%$ of the Australian continent). The GAB's ground surface is characterized by semiarid regions with land uses that often rely on access to groundwater, and it is considered the lifeblood of much of Australia's interior for Indigenous peoples (the Aboriginal and Torres Strait Islander peoples, who are the Traditional Owners of the land), and for landowners, agriculture and industry. Water use in the region allows for $\mathrm{A} \$ 12.8$ billion in economic activity annually (Frontier Economics 2016). The GAB aquifers support many springs, which are associated with important groundwaterdependent ecosystems (GDEs) and Indigenous livelihood, cultural values, traditions and spirituality (e.g. Ah Chee 2002; White and Lewis 2011; Moggridge et al. 2019). The Australian Indigenous culture is the oldest living culture on Earth, thriving for thousands of years on the driest inhabited continent, in great part because of the access to water and food from artesian springs and associated GDEs. Aboriginal peoples have strong cultural and spiritual connections to water and land, which are protected by lore, the customs and stories

Published in the special issue "Advances in hydrogeologic understanding of Australia's Great Artesian Basin"

Carlos Miraldo Ordens

c.ordens@uq.edu.au

1 Centre for Water in the Minerals Industry, Sustainable Minerals Institute, The University of Queensland, St Lucia, Brisbane, Queensland 4072, Australia

2 Centre for Natural Gas, The University of Queensland, St Lucia, Brisbane, Queensland 4072, Australia

3 Geoscience Australia, Canberra, ACT 2609, Australia

4 CSIRO, Brisbane, Queensland 4102, Australia

5 CSIRO, Adelaide, South Australia 5064, Australia they learned from the Dreamtime, present in songs, dance, Dreaming stories and art. Lore establishes the responsibility of Aboriginal people to look after the water, which is part of what they consider to be a single connected system that includes the land, people and all living beings.

The GAB is a complex groundwater basin composed of four main geological basins: Eromanga, Carpentaria, Surat and Clarence-Moreton. It is represented by a sedimentary sequence deposited from approximately 200 to 65 million years ago (Jurassic and Cretaceous periods) comprised largely of alternating sandstone, siltstone and mudstone beds that constitute aquifer and aquitard units. This sedimentary sequence reaches a thickness of $\sim 3,000 \mathrm{~m}$ in the central part of the Eromanga Basin (Ransley et al. 2015). The GAB largely overlays deeper, older geological basins (e.g. the Bowen and Galilee basins) and is overlaid by newer surface drainage divisions and associated alluvium (e.g. the Lake Eyre and Murray-Darling river basins; Smerdon et al. 2012). In general, GAB aquifers outcrop and are recharged by modern rainfall along its eastern and, to a lesser extent, along western margins (Habermehl 1980, 1982; Radke et al. 2000; Keppel et al. 2013). Groundwater flows are generally conceptualized as deriving from the eastern towards the southern, western and northern margins, and from the western margin towards the south-west (Habermehl 1982). A long-lasting conceptual description of the GAB was of a single, large, contiguous groundwater flow system in which aquifers were considered to be laterally continuous across the extent of the basin. This description was improved by the findings of Smerdon et al. (2012), which identified key geological complexities. These include multiple layers with varying groundwater flow rates, connections with overlying and underlying basins, vertical connections between aquifers and the presence of faults that can either act as lateral barriers to flow or as conduits between aquifers. This special issue further advances knowledge that leads to updated and refined $\mathrm{GAB}$ conceptual understandings.

The GAB's total groundwater volume has been estimated at around 65,000 million ML by Hillier and Foster (2002), which is about 130,000 times more than Sydney Harbour's storage 
(Geoscience Australia 2019) and corresponds to around 9 years of the Amazon River (world's river with highest flow) total discharge (FAO 2016). GAB groundwater is of meteoric origin with ages that range from modern in the recharge areas to over 1 million years in the central basin (Habermehl 2001). Most of the basin has artesian conditions and its old groundwater is thought to be relatively well protected from the effects of climate change, except in the small proportion that corresponds to recharge areas. As such, it is a strategic water resource that offers a buffer against the expected future increase in severe droughts. On the other hand, GAB groundwater is mostly nonrenewable on planning time scales, and as such needs to be managed carefully to minimise negative effects on spring discharges and access to water for human activities. The basin has been subject of scientific investigations and management programs since the early 1900s, which continue to the present date. The most recent examples are the continuation of the bore-capping program that aims to reduce the losses through uncapped artesian bores (Business Queensland 2019), and a GA-lead project that aims to better estimate the GAB's water balance (Geoscience Australia 2018). A comprehensive description of the history, hydrogeology, importance (environmental, social, economic and cultural) and management of the basin is provided by a review paper in this special issue, which is summarised in section 'History of the GAB'.

Despite its multi-dimensional features, the GAB is still largely perceived today, and to some extent managed, according to historical hydrogeological conceptual models that are inconsistent with recent research findings. These concepts give rise to oversimplistic and in some cases even incorrect public understanding of the basin, and therefore misinform the public about risks to groundwater. Examples of new findings that are not generally considered in GAB management are (1) interconnectivity across aquifers and subbasins, (2) role of faults on local and regional hydrogeology, (3) recharge processes, (4) climate-change impacts, (5) spring hydrology, and (6) impacts of human activities on GAB's water quality and balance. The last 10 years have seen a large increase in available data and a corresponding large investment in improving scientific understanding of the GAB's hydrogeology and socio-hydrogeological connections, including in areas that have undergone intensive monitoring and assessment prior to and during coal seam gas (CSG) extraction or mining (particularly in the Surat Basin region of the GAB). This accelerated growth in understanding over the last 10 years is the basis for this special issue, which aims to collect and disseminate the most recent science on the GAB. More specifically, this special issue aims to contribute to updated conceptual understanding of the GAB that can lead to better-informed discussions and management of the basin. This special issue also explores how the knowledge gained from intensive work conducted in the Surat Basin can inform research and management in other parts of the GAB.
One feature of this special issue is that it is a highly collaborative initiative that combines research done across institutions such as universities, research agencies, government departments, and CSG and consultant companies, often with manuscripts being co-authored across institutions. As well as encouraging the publication of peer-reviewed science from organisations that are not accustomed to doing so, it has forged multi-institutional collaborations for continuing studies and for more effective management of the GAB into the future. The special issue will be followed up by a public engagement and communication program aiming at communicating the science of the GAB to the general public, including a website and the delivery of a range of educational materials. Dissemination to the science community included a special session dedicated to the special issue contents at the Australasian Groundwater Conference in Brisbane in November 2019, hosted by the International Association of Hydrogeologists (IAH) and the National Centre for Groundwater Research and Training (NCGRT).

The special issue is comprised of 26 articles, including a review paper on the history of the basin, and a profile of eminent researcher Justin Costelloe. Fourteen articles focus on the Surat Basin of Queensland, which saw a large expansion of the CSG industry over the past decade that led to the need to research the potential impacts of this industry on groundwater. Four articles focus on the Western Margin of the GAB, which was the subject of a large research study that began in April 2008 sponsored by the Australian National Water Initiative (NWI) to "...obtain a greater understanding of the complex hydrogeological and ecological systems in the western margin of the GAB" (Keppel et al. 2013). Three articles study the GAB as a whole, while another three articles focus on other $G A B$ regions. This spatially uneven distribution of contributions reflects the areas of priority interest for research funding. Many of the manuscripts offer methodological guidance relevant to less intensively studied parts of the basin, and/or other geologically complex continental-scale aquifer systems. The manuscripts are organized in the following topics: (1) history of the GAB; (2) eminent researcher; (3) groundwater flow processes, which includes compartmentalisation and connectivity, aquifer flows (pathways, rates and heterogeneity), numerical modelling, and springs and GDEs; (4) groundwater governance and management tools. This preface provides a summary of each paper, organised into these topics, with synthesis that offers the guest editors' (special issue organizers') view of the scientific and practical significance of the papers within and across topics.

\section{History of the GAB}

The special issue starts with a comprehensive review of the GAB by Habermehl that includes the history of the GAB 
discovery and its exploration, scientific investigations (hydrogeology, hydrochemistry, isotope hydrology, groundwater modelling) and governance, and that summarizes the most recent knowledge of the GAB as a complex groundwater socio-ecological system. Importantly, the paper describes the several management programs implemented in the basin for the last century, reflecting on their contributions to sustainable basin management. The paper provides the reader with a unique insight into the coevolution of exploitation, knowledge and management of a major basin for over 100 years; and provides a historical context that is necessary for readers to appreciate the practical drivers and significance of the other special issue papers.

\section{Eminent researcher}

Western et al. reflect on the contributions of the recently deceased Justin Costelloe to the GAB's hydrogeology and beyond, and is an excellent testament of his legacy. Costelloe was a leader in Australia's arid-zone surface-water and groundwater hydrology, and made important interdisciplinary contributions linking the hydrology and ecology of the arid zone, with a focus on the GAB and overlaying Lake Eyre Basin. His GAB-related research demonstrated the influence of groundwater discharge in catchments of high-salinity waterholes and streams, and he worked on quantifying the salt discharge fluxes from GAB aquifers to surface water. Costelloe was the first to use field measurements to better constrain GAB losses through vertical leakage in the GAB's southern margin, which is an important component of the basin's water balance that was used for basin-wide models. Besides applying field-based techniques, Costelloe and colleagues also applied remote sensing to upscale local observations to basin-wide classification of vertical discharge rates. Costelloe was not just a prolific researcher, he also provided advice to the government on arid-zone hydrology management and was regarded as a great mentor to students. The hydrological community of Australia is certainly much poorer since he passed away in 2018, but will hopefully be inspired by his research, teaching and enthusiasm on protecting precious natural systems such as the GAB.

\section{Groundwater flow}

Groundwater-flow processes are a key research focus in the GAB. As explained by Habermehl, the geology and the hydrogeology of the GAB are complex and still subject of many research questions. Many of these questions relate to hydrogeology conceptualisation of the basin across different scales, from boreholes to aquifers to subbasins to the whole of the GAB. This includes, but is not limited to, the role of faults in groundwater flow processes, interconnectivity between basins, structural influence on groundwater flow processes, groundwater recharge, and impacts of climate change.

\section{Compartmentalisation and connectivity}

Radke and Ransley explore the evidence for vertical connection (or not) between GAB aquifers and the 27 sedimentary basins currently known to underlie the GAB. Intra-basin connectivity can occur through both the contact of permeable units at basin boundaries and along permeable segments of faults. 'Connectivity potential' across the basement of the $\mathrm{GAB}$ is portrayed by using this categorisation on units that are in direct contact across the boundary. The basement of the GAB is a patchwork of older sedimentary basins, from Paleoproterozoic to Triassic age, and also includes regions of metamorphic and crystalline basement. The GAB sequence has variable Paleogene-Neogene cover. In the eastern Eromanga and Surat-Clarence-Moreton regions, this cover is minimal, whereas the western Eromanga region east of the Denison-Willouran Divide is almost completely covered by the Lake Eyre Basin. Similarly, in the Carpentaria region, the Karumba Basin offers complete cover offshore as well as almost entirely onshore, apart from the easternmost margin. This paper demonstrates that simplified single conceptualizations of the GAB and its vertical and lateral extent are outdated. There is a range of connectivity that is gradational and "fuzzy" or difficult to quantify since the degree of hydraulic connection correlates to the time period being considered by analysis. Depending on the time scale of the problem, the relevant strata that might be considered to be hydraulically associated with GAB systems are different and transient.

Sandiford et al. focus on understanding the link between deformation of surface landscapes and surface hydrology of the Lake Eyre Basin, and deep aquifers in the central part of the GAB, aiming at a better characterisation of the basin's groundwater dynamics. Exploring the connection between fault-associated tectonic landforms with a potentiometric anomaly, they build on recent GAB observations to show that surface-channel derangement indicates an active, deep, northnorthwest fault system with displacement in the order of $100 \mathrm{~m}$, which likely accrued over a 1-million-year period. The authors offer a conceptual model on the impact of faultrelated occlusion in groundwater pressure in the deep $\mathrm{GAB}$ artesian aquifers, discuss the complexity of tectonic processes manifested in the landscape and speculate on their contribution to the GAB aquifer systems' temporal evolution. They conclude that (1) surface drainage systems across central and eastern Australia suggest ongoing mild tectonism over the last 1-million-year period that continues to modify the landscape; (2) the distribution of Lake Eyre Basin's drainage system evidences an active fault system that correlates with compartmentalisation of deep aquifers in the central part of 
the GAB; and (3) correlations in the distribution of seismic activity, surface drainage and lithospheric thickness suggest that stress sourced from sublithospheric mantle flow has played an influential role in shaping the GAB architecture. Their work on understanding tectonic compartmentalisation and timing of deformation of geological formations has implications for new hydrogeological conceptual models, and consequently provides constraints for water-balance studies of GAB aquifers where aquifers may be inferred to be compartmentalized by subtle recent structures.

\section{Aquifer flows: pathways, rates and heterogeneity}

Suckow et al. investigated the effective deep recharge to the Hutton Sandstone within the area of the Mimosa Syncline, a major confined aquifer of the GAB's Surat Basin, which has been quantified for the first time with the aid of environmental tracers: major ions, stable isotopes and helium. Groundwater flow velocities calculated from applying the environmental tracers ${ }^{14} \mathrm{C}$ and ${ }^{36} \mathrm{Cl}$ resulted in a factor-of-ten discrepancy between both tracer methods. The study reconciled these contradictory results by considering the Hutton Sandstone as a dual porosity system, in which a significant part of the tracer is not only lost by radioactive decay, but also by diffusion into lower-permeability stagnant zones of the aquifer. The conceptual and mathematical description of this process allowed effective deep recharge to be estimated as $3 \%$ of earlier estimates that employed a chloride mass balance. Suckow et al. argue that chloride mass balance probably gives a correct shallow infiltration rate but most of that infiltration is "rejected recharge" diverted to springs and surface water, with only a small fraction of recharge reaching the deeper system. These results are significant for quantifying groundwater resources in deep confined systems. The authors suggest that the presented dual porosity reconceptualization is likely applicable to a significant number of earlier studies that apply environmental tracers to old groundwater, as well as to systems that include old groundwater and that have limited spatial and temporal coverage of tracer data such as the GAB. Vink et al. similarly present evidence of a dual-porosity system for the Hutton Aquifer with some areas/intervals well connected hydraulically and other areas having significantly lower permeability characterized by low groundwater fluxed and relatively more mature water chemistry.

Vink et al. reinterpret groundwater flow processes in the Hutton Sandstone, with detailed analysis of recent data for the Dawson River area in the northern Surat Basin. They combine analysis of high-resolution permeability measurements with hydraulic head and hydrochemistry, concluding there is significant flow towards the northeast, which contradicts the GAB's "canonical" regional flow conceptualisation. The authors identify the area in which the Dawson River intersects the Hutton Sandstone as the likely discharge area of the aquifer. They interpret the local flowpaths as more complex than previously thought and defend that, at least in their study area, very little recharge reaches deeper layers of the basin. This is in accordance with the conclusions of Suckow et al., who reached similar conclusions based on hydrochemical and isotopic data. Importantly, Vink et al. affirm that their results provide an updated conceptual understanding of the Hutton aquifer, which can be used for improved regional groundwater numerical models.

Often as new data are obtained, the conceptual complexity of aquifers increases, including their sedimentary, stratigraphic and structural architecture, together with their distribution of rock properties - porosity, permeability, thickness, transmissivity and storativity. An example of this, as well as emerging methods for description and quantification, is described by Gaede et al. The Late Jurassic Springbok Sandstone in the Surat Basin presents high lithological and hydrogeological heterogeneity, which is poorly defined in bore logs, due, in part, to clay phases that do not exhibit a prominent gamma ray signature. The resulting uncertainties in the hydrogeological properties are propagated to uncertainties in the groundwater models. The authors present new porosity and permeability data from more than 50 core samples from the Springbok Sandstone alongside a review of existing data. Based on this dataset and wireline data from five study wells, a new petrophysical model for the formation is demonstrated. It is concluded that the petrophysical model can more accurately predict the hydraulic property distribution in the Springbok Aquifer. Based on the analyses, it is determined that the Springbok Sandstone, although indiscriminately labelled a sandstone, is largely not a sandstone but shows significant variability in clay content. The workflow presented provides a guide for the characterisation of aquifer properties in the Springbok Sandstone and similar lithologies. In combination with 3D geological models, the results can be utilized to more accurately predict the lateral continuity of strata that have the sufficient transmissivity to constitute aquifers.

Pandey et al. report a study on the hydrogeological connectivity between two aquifers in the Surat Basin's geographical extent. In parts of the basin, the phreatic Condamine Alluvium directly overlies the Walloon Coal Measures, which is a GAB formation targeted for CSG production. To investigate the connectivity between the two systems, multiple lines of investigation were employed involving reinterpretation of geology, multi-variate hydrochemistry analysis, groundwater level analyses, drilling and coring across the contact zone, pumping tests, and local-scale modelling. The study found a low level of connectivity between the GAB aquifer and the overlying Condamine Alluvium. A clay layer was identified that is referred to as a "transition zone", composed of a mixture of alluvial clay and weathered basement, which provides an effective impediment to flow between the two aquifers. Results from the study have potentially wider applications 
across the GAB and other sedimentary basins, especially where river-associated younger alluvial sediments overlie erosional surfaces of deeper aquifers.

Owen and Herbert explore heterogeneity within hydrogeological units using hydrochemistry data. This is valuable where local-scale hydrogeological conceptual models are needed such as in CSG development areas, or where larger-scale model outputs are sensitive to parameterization assumptions. In the case study, water samples from CSG production wells, which produce both gas and water in the Walloon Coal Measures of the Surat Basin, were analysed for major and minor ions. The paper presents a methodological advance in the demonstration of compositional data analysis using centred log-ratios of the ion concentrationsprincipal component analysis using scaled and transformed data - and subsequent clustering. The authors contend that using the original ionic concentration and $\mathrm{pH}$ data and using conventional hydrochemistry clustering approaches can lead to errors interpreting groundwater source intervals within a well. Instead, they apply logistic regression to properties of the centred log ratio components to predict the probability that any sample was taken from a given subunit. The determination of different subunit hydrochemistry has clear local applicability for more finely stratified hydrogeological modelling within the studied $10 \mathrm{~km}^{2}$ or so area of the Surat Basin. This has detailed application, for example, in the analysis of the hydraulic nature of faults.

Viljoen et al. offer the first detailed evaluation of fault hydraulic behaviour in the eastern Surat Basin using seismic reflection surveys and subsequent drilling to test the Horrane Fault. This work has demonstrated that there has been very little or no fluid movement along the fault and its associated fractures. The step-rate test results further suggest that the permeability is very small in the vertical direction along the fault zone. The interpreted fault hydraulic conductivity is lower than that in the Springbok Sandstone which may explain why pressure differences are observed in the Springbok Sandstone across the fault. Beyond the mapped extent of the fault there is not a clear demarcation of water pressures, which suggests that the impact of the fault may be local. Conceptual models are often based upon the premise that hydraulic connectivity is possible by direct linkages between aquifers due to faults. This study suggests that conceptual models where faults provide groundwater barriers are equally possible and it is therefore reasonable to consider a range of conceptual models of groundwater impact from resource development.

\section{Numerical modelling}

Hayes et al. present new geological and hydrogeological interpretations of the Precipice Sandstone aquifer within the Surat Basin, showing a more limited lateral extent, with greater geological and permeability variability than previously understood, especially across the northern Surat. These findings were based on a combination of interpretation of regional two-dimensional (2D) seismic lines and calibration with 3D seismic data, facies analysis of cores, and calibration with petrophysical data that support a reduced extent of the Precipice Sandstone aquifer. This geological information was considered in conjunction with two managed aquifer recharge (MAR) schemes that injected over 20 GL of water into the Precipice aquifer, with pressure responses propagating over $100 \mathrm{~km}$. Groundwater modelling of injection and inversion of pressure observations indicates high spatial variability in aquifer properties, and that the basin's in-situ stress regime and faulting exert control on permeability. The broader-scale estimates of permeability derived using the MAR observations were higher than found in previous studies, which has implications for the management of water resources in the Precipice aquifer.

Sreekanth et al. provide a case study where they develop a regional-scale numerical groundwater model using MODFLOW-USG to probabilistically assess potential groundwater impacts due to additional coal resource development from a deep sedimentary basin. The probabilistic simulation considered the plausible variability of the hydraulic characteristics of aquifers and aquitards within the sedimentary basins. The predictive simulations were undertaken using 2,618 model runs to obtain maximum head drawdown caused by CSG and coal-mining developments. The paper represents significant advances in groundwater impacts assessment that have been made within the Australian Government's Bioregional Assessment program. In particular, the paper addresses the range of challenges encountered when attempting probabilistic predictions of impacts. This includes the necessary simplification of the conceptual model, the use of emulator (regression) models for generalising the impact assessment beyond a few scenarios, and the use of model stress testing and global sensitivity analysis. The challenges of dealing with complexity, model size, numerical tractability and scenario design are now critical practical considerations in groundwater modelling, and these challenges will intensify as GAB conceptual models develop in complexity and as multi-scale modelling of the GAB becomes increasingly demanded. Inferences can be drawn from this work on the general hydraulic connectivity among GAB aquifers of this subregion. Similarly, there are implications regarding the effectiveness of recharge efficiency in this area to deeper GAB aquifers. Away from outcrop areas, the heterogeneity and lack of vertical hydraulic connectivity of the system generally inhibits recharge to deeper aquifers.

\section{Springs and GDEs}

Flook et al. present a conceptualisation study of spring hydrogeology, including identification of source aquifers, in the 
complex, multi-layer aquifer system of the Surat Basin, focusing on two different spring types, the Lucky Last (permanent wetlands) and Abyss (semipermanent, diffuse discharge) spring complexes. Their approach included data collection and analyses of geology, hydrogeology, geophysics, hydrochemistry and isotopes. They extended monitoring to and offer broad analyses of 15 other spring complexes of the Surat Basin. A key outcome from the work of Flook et al. is a revision of source aquifers to selected spring complexes of the Surat Basin, including the identification of fault-driven groundwater sources as well as diffuse discharge. More broadly, the conceptualisation of 17 spring complexes across the study area provides insights into the occurrence of springs on the GAB's eastern margin: (1) groundwater flow along subsurface geological structures or the contact between geological units is the dominant control on groundwater flow to springs; (2) erosion and dissection are the dominant surface processes that control the location of spring-associated wetlands; (3) many wetlands receive groundwater inflows from both regional (deep) and local (shallow) systems; and (4) some springs and associated wetlands are ephemeral, and seasonal changes in evapotranspiration demand have a significant influence on the extent of the wetlands. As well as new knowledge of the hydrology of these spring complexes, the work is a good example of how a multi-dimensional conceptualization procedure can deepen insight.

Jones et al. report on ground-truthing GDEs, and updating respective conceptual models, in the Surat Basin using four sites dominated by river red gum, mapped as GDEs by government agencies. They applied a combination of field-based methods to ground truth the occurrence of assumed GDEs. Their methodology was comprised of (1) soil coring to observe tree rooting depth and underlying hydrogeological conditions, (2) matching of soil moisture with leaf water potential, and (3) analysis of naturally occurring hydrogen and oxygen stable isotopes in tree xylem, soil moisture and groundwater. The results show that trees in (at least) three sites were predominantly utilising soil moisture (and not GAB groundwater), and that rooting depths of studied trees were consistently much shallower (maximum depth of $7.6 \mathrm{~m}$ ) than typical literature values (12-22.6 m). Their findings highlight the importance of multi-method ground truthing of mapped GDEs in government databases, especially in areas subject to heavy groundwater abstraction.

Priestley et al. focus on the hydrochemical variations of groundwater and spring discharge in order to determine the major geochemical processes responsible for water quality and evolution across the western GAB. Regional chemical variations along groundwater flow paths in the western $\mathrm{GAB}$ are complex, which are a function of several controlling processes, including location of recharge, evapo-concentration, mixing and water-rock interactions. The authors found that these processes cause groundwater east of Lake Eyre to be predominantly of the $\mathrm{Na}-\mathrm{HCO}_{3}$ type, whereas groundwater originating from the western margin is of $\mathrm{Na}-\mathrm{Cl}-\left(-\mathrm{SO}_{4}\right)$ type. The GAB springs appear to be discharging water predominantly from the main GAB aquifer in the region- the $J$ Aquifer. However, the authors affirm that a component of the discharging water from several springs is from a source other than the J Aquifer. The updated understanding of the hydrochemical variations of groundwater and spring discharge of the western Great Artesian Basin can help provide constraints on groundwater flow, as well as provide an understanding of the geochemical and hydrological processes responsible for water quality evolution. Priestley et al. suggest further work is still needed to better characterise water-rock interactions and geochemical processes occurring within the $\mathrm{J}$ Aquifer and to characterise and quantify the sources of the GAB springs.

Wolaver et al. studied the Dalhousie Springs (Dalhousie) group, which is the largest spring complex in the western $\mathrm{GAB}$, accounting for $\sim 40 \%$ of GAB spring discharge. These springs support groundwater-dependent ecosystems over an area of $\sim 200 \mathrm{~km}^{2}$. Using multiple lines of evidence, this study identified that the Permian Crown Point Formation is an important contributor to the spring discharge at the Dalhousie Spring Complex. The contribution from this formation was previously unrecognized, and the revised hydrogeological conceptual model presented here identifies both the overlooked Permian aquifer and other deep fluid sources as providing groundwater discharge to Dalhousie, in addition to previously accepted contributions. The most plausible mechanism for Permian and Jurassic-Cretaceous aquifer discharge at Dalhousie is through fault-associated fractures in the McDills-Dalhousie Ridge anticline. Preservation of Dalhousie requires that the potentiometric surface in the vicinity of Dalhousie be maintained at or near present levels in both Permian and Jurassic-Cretaceous aquifers. The conclusions of this paper add to the notion that fault-zone hydraulic properties - both high and low depending on the nature of the fault zone and its displaced strata-form critical hydraulic elements to a conceptual and numerical groundwater model. These aspects can be tested with field observations and used for calibration of dynamic models in order to improve forecast capacity.

Keppel et al. investigated the correlation between recent seismicity and springs located within the south-western GAB. At a regional scale, evidence is provided by the development of springs in close association with regional faults within a previously identified zone of enhanced seismicity. At a local scale, veins and lineaments were found to be conformable with the underlying regional shear. They conclude that ongoing reactivation of faults has affected mound spring morphology as evidenced by deformation of mound spring deposits. As many springs are carbonate-depositing, active seismicity may have an important role in relation to the maintenance of 
the spring conduit systems. The concordance of structural deformation in spring carbonates with that of underlying regional structures indicates that these basement structures have been reactivated and propagated through overlying basin sediments through ongoing intraplate tectonic activity. Neotectonics may have a significant impact on the GAB's hydrogeology, including: (1) the development of heterogeneous porosity and permeability, (2) the development of direct and diffuse discharge and (3) fault-related interconnectivity between aquifer units or compartmentalisation divides of the GAB into subbasins. Consequently, thorough hydrogeological characterisation of such structures is critical given growing concerns for the preservation of associated ecologically fragile spring environments. This article is in agreement with Wolaver et al. and Halihan et al., giving evidence for the importance of faultzone hydrology for GAB conceptual and numerical groundwater models.

Halihan et al. studied the groundwater origin of and potential groundwater mixing at the Freeling Spring Group, South Australia, at the GAB's Western Margin. The authors combined groundwater chemistry from five springs and a well with electrical resistivity imaging (ERI) data, which allowed them to evaluate the springs' groundwater sources and pathways. This also permitted them to look for evidence of groundwater mixing between the GAB and the adjacent mountain block aquifers. The resistivity data indicate three independent electrically conductive curvilinear features connected to the spring, which are consistent with traditional hydraulic flownets and are evidence of mixing at the spring vent. Spring hydrochemistry indicates that the water emanating from the Freeling Spring Group is a mixture of waters from both the GAB and the mountain block (MB) basement, supporting the geophysical evidence. The data suggest that mixing occurs along a fracture in the body of the MB aquifer and porous media flow in the GAB beds, but that the system is dominated by the GAB flow with approximately $90 \%$ of the discharge. This work contributes to understanding the hydrogeology of the Freeling Spring Group, which has implications for the management and preservation of Western GAB springs.

Matic et al. applied remote-sensing methods to better understand spatial and temporal variability of GAB losses through upward vertical leakage. They focus on the GAB's southwest margin, which features large areas where artesian groundwater is discharged at high rates through near-surface diffuse discharge, typically associated with GDEs, and characterised by high soil-moisture contents and salinization. They used landform mapping and a field-validated, semiautomated remote-sensing approach for discharge classification, aiming at (1) improving classification results previously obtained by single-image classification, (2) providing a wide coverage of classes and improving confidence in areas without field-trained classification, and (3) detecting temporal trends and questioning the steady-state assumption. They conclude multi-image classification integrated with landform data significantly reduces uncertainty by reducing false positives. No significant temporal discharge trends were found, which the authors interpret as the assumption of steady-state discharge being valid for estimating annual vertical leakage. Nevertheless, time-series results showed patterns the authors attribute to image normalisation issues that can be improved in future work. Their contribution has important management implications because it provides lower and upper bounds of the GAB's vertical leakage rates associated with discharge, and also provides results on a novel GDE classification for the GAB's southwest margin.

\section{Groundwater governance and management tools}

Robertson examines the governance framework regulating Queensland's GAB portion with a focus on the Surat Basin, where there is extensive development involving multiple water uses (e.g. domestic, pastoral, agricultural, CSG and town supply). The paper analyses the limitations of the framework in preventing declining groundwater levels in parts of the basin, conflict between water users and lack of trust in governance arrangements. The paper (1) considers the objective of sustainability in the context of groundwater resources and Common Pool Resources scholarship, (2) presents a summary of the regulatory framework governing access to water in the Surat Basin, and (3) analyses this framework in terms of Ostrom's Common Pool Resources design principles (Ostrom 1990). The author presents a case that most of Ostrom's design principles are absent in current governance arrangements and suggests that this may contribute to the sustainability challenges of the Surat Basin. The author highlights various reform measures that could be adopted but also cautions against applying institutional design principles without considering political and social aspects. The author's analysis of historical governance arrangements supports the need for a more inclusive approach, which is in accordance with recent research conducted in other Australian examples. The author recommends the state adopt authentic, respectful and effective engagement with stakeholders, including citizenscience initiatives. Together with presenting new information on the status of the GAB, this can stimulate collectively supported equitable outcomes and collective learning. Robertson concludes that serious GAB sustainable management requires learning from its management history, acknowledging past challenges and working towards an empowering relationship between groundwater users and regulators.

Wolhuter et al. describe the design and structure of the 3D Water Atlas and illustrate using the Surat Basin as a case study. The 3D Water Atlas is a freely available web-based interactive 
three-dimensional visualisation and analysis tool for groundwater and hydrogeochemical data. It combines bore datalocation, construction, hydrochemistry and groundwater levels - with a geological model and complementary spatial datasets. The 3D Water Atlas is different from other groundwater visualisation tools as it allows users to freely visualise all data within a 3D scene, and provides quality control and multiple visualisation options for groundwater data - e.g. bore hydrographs, pie charts and animations of major ionswithout requiring downloading or specialist software. The tool supports community consultation and shared understanding of the hydrogeological system, which is particularly important for highly complex systems such as the Surat Basin. The 3D Water Atlas exemplifies the accelerating availability of groundwater visualisation tools now available for the GAB and internationally, as reviewed in the paper.

Fu et al. provide the first integrated climate change and variability study of the $G A B$, which is critical for $G A B$ groundwater management. Historic climate observations show that the GAB region had become warmer (temperatures increased by $\sim 0.020^{\circ} \mathrm{C} /$ year) and wetter (annual rainfall increased by $0.95 \mathrm{~mm} /$ year) during the period 1960-2016, although there is significant spatial variability. Trends of other rainfall statistics associated with recharge indicate an increase of the 95th percentile of daily rainfall, an increase of average rainfall intensity, and a statistically significant decrease of the mean length of the wet spell. Future climate projections from the Intergovernmental Panel on Climate Change (IPCC) Fifth Assessment Report (AR5) shows 40 general climate models (GCMs) that indicate the GAB region would be warmer and drier in the future. There is a large uncertainty in recharge predictions for the GAB under various climate change scenarios (projections for up to a $41 \%$ decrease in recharge under dry scenarios or a $51 \%$ increase in recharge under wet scenarios), although this is not uniform throughout the GAB. According to $\mathrm{Fu}$ et al., priority future research on groundwater management and hydrogeology under climate change scenarios includes: (1) identifying the most suitable GCMs for the GAB; (2) predicting groundwater abstraction under future climatic conditions; (3) investigating the impacts on springs and GDEs; and (4) exploring the impacts on cultural values for Indigenous people and economic activities.

Historical and current estimates of groundwater abstraction are critical for conceptualisation of groundwater systems, for understanding system responses to pumping, and to effective groundwater management. An important challenge for managing regional aquifer systems is lack of pumping data. Consequently, analytical estimation methods are typically the solution despite the large uncertainty associated with them. Kent et al. and Singh et al. attempt to address these critical issues for the management of GAB aquifers in Queensland, and present methodologies for estimating groundwater pumping at regional scale. Their work has important implications for regional groundwater management and provides key lessons for others attempting similar estimations elsewhere in Australia and internationally. One important lesson from their articles is that an important challenge for managing regional aquifer systems is lack of pumping data, which in turn makes validation of estimation methods and reduction of uncertainty difficult.

Kent et al. developed a methodology to estimate current and historical abstractions from the aquifers of Queensland's GAB portion for the period 1900-2015. They used publicly available datasets to (1) assign source aquifers to $\sim 96,000$ bores and (2) estimate historical and current groundwater use for all bores, with resulting important groundwater management implications. Groundwater use estimates for the study area were of $\sim 322$ GL in 2015, which is lower than previous estimates. The authors attribute this difference to (1) improved estimation techniques, (2) the bore capping and piping programs that have been in progress since 1989 , and (3) the naturally reducing discharge rates from uncontrolled artesian bores. Coupled with predicted emerging demand, this helped to identify areas of potentially increasing groundwater use.

Singh et al. provide a methodology for estimating temporal and spatial distribution of groundwater abstraction for stock and domestic purposes in the Surat CMA. Stock and domestic groundwater extraction is generally not metered in Australia, although it can be a significant component of groundwater balance. They developed a demand-based analytical method integrating publicly available datasets (i.e. property grazing potential and availability of other water sources), which was validated with available metered data and census data and landholder survey information at the subregional level. Their results show an estimated reduction in stock and domestic water extraction from approximately 80,000 to $25,000 \mathrm{ML} / \mathrm{year}$ when compared to previous estimates. They emphasize that the reduced availability of metering data is a limiting factor for their work, and that continuous and more comprehensive monitoring is needed.

Witt et al. aimed to understand public perceptions and acceptance of enhanced water recovery (EWR) as a new technology to both mitigate climate change and groundwater depressurisation in the Surat Basin. In EWR, carbon dioxide $\left(\mathrm{CO}_{2}\right)$ is captured from the atmosphere and stored in deep confined aquifers. This technology is based on the premise that $\mathrm{CO}_{2}$ injection into deep aquifers increases hydraulic pressure, making groundwater, within these aquifers, more easily available at shallower depths across a broad region, while simultaneously contributing to a reduction in atmospheric $\mathrm{CO}_{2}$ concentration. They conducted focus groups in both regional and urban areas to understand how different groups perceived EWR risks and benefits, and compared those with perceptions of MAR schemes. The results show that although most people were interested in learning more about the 
technology, EWR was not generally accepted. For many, the cost of the technology and the risks of aquifer contamination did not outweigh the perceived benefits. Interestingly, initial landholder responses to MAR in previous studies were similar to the focus group reactions to EWR found by Witt et al., and yet many are now comfortable with the MAR concept. The authors suggest that this demonstrates the importance of social norms and local context for technology acceptance, and suggests opportunities for research trials that may build more confidence in the process if positive. Additionally, this study highlights how levels of knowledge about the GAB and its management remain low in both urban and regional communities. Many participants expressed a desire for more education and communication on GAB's sustainable management, and on the need to deal with carbon emissions.

Jamieson et al. report the first study of citizen science applied to groundwater management in Australia. The case study is GAB's Surat Basin. Such context is particularly challenging because, besides the lack of monitoring data needed to manage impacts on groundwater, there are trust issues between local stakeholders, resource companies and regulators. The paper adds to the knowledge of how to apply citizen science to help resolve groundwater problems, including the social and engagement dimensions. It discusses how government agencies can use community-based groundwater monitoring to empower and educate borehole owners, engage them in groundwater-management issues, and improve local groundwater management in areas where groundwater data are scarce and where there are potential conflicts of interest regarding groundwater resources. It reflects on the program design, implementation and continuation, and offers lessonslearned for those interested in implementing equivalent programs elsewhere. Jamieson et al. conclude that the program was most effective when engaging local community leaders and existing associations. It contributed to increases in the size of the GAB groundwater-level-monitoring network in the area, expansion of the network into areas where CSG industry or government monitoring did not exist, and reduction of borehole investigations. The large majority of landholders who attended workshops found the program valuable and improved their understanding of groundwater. Jamieson et al. argue that this approach could be adopted wherever there are competing interests for groundwater resources, in Queensland, Australia, and internationally.

\section{Conclusions}

At the start of this preface it was pointed out that the GAB's groundwater can be considered nonrenewable on planning time scales, and as such, care is required to ensure that this important resource is not squandered. The GAB is Australia's largest and most important groundwater resource that sustains
GDEs as well as providing drinking and agricultural water supplies. As Australia begins to consider management of water resources in changing climatic conditions, the implications of the new insights provided in the studies described above that evaluated flow pathways, aquifer interconnectedness, and the provenance of recharge sources, must be considered carefully in any management scenario. Further, these features must be represented either implicitly or explicitly in any numerical model built to support the management decision process. This special issue contributes to an overall increased understanding of the GAB's hydrogeology and groundwater management. A summary of the main findings follows.

The GAB geology - temporal tectonic evolution, stratigraphic correlations, structural geology, in-situ stress and strain, and geological heterogeneity-is far more complex and heterogeneous than previously understood. This has important implications that include our understanding of hydraulic continuity (or lack of) of subbasins and aquifers - for example, the base of the GAB is not a clear boundary but is gradational and variable geographically, and evolves on the 1-million-year timescale due to mild tectonism. This heterogeneity and consequent complexity are represented in several articles that focus on groundwater-flow processes relating to conceptualisation or modelling of the basin across different spatial scales, from boreholes to the whole of the GAB. This has obvious implications for how one conceptualizes hydrogeological processes in the GAB, and it provides challenges to the development of new ways of thinking about how the flow systems should be represented in numerical models and about how one should interpret water level and hydrochemistry data. There are both challenges and opportunities to work with an ever-increasing density, resolution and extent of data; the adoption of advanced data analytics, automated data processing tools, and $3 \mathrm{D}$ visualisation could result in an unprecedented knowledge base to underpin conceptual and numerical modelling, and ultimately, groundwater management. This is particularly evident in the case of the Surat Basin, where field data include petroleum-industry investigation methods of high-resolution downhole and surface geophysics, laboratory core analysis and the application of advanced isotopic methods. In both regional-scale modelling, where the new data must inform upscaled representations, and in local-scale modelling, where the new data may be more directly used to construct the model, there is a continuing need to ensure that new data sets are exploited. The special issue articles collectively drive us to recognise the exponentially increasing volumes of data available, including satellite and other geophysics data, the increasing role of big data management and visualization, and initiatives to turn big data into better conceptual and numerical models, bringing these often-isolated pockets of data together.

Recharge processes are complex and space and time dependent. How much water currently recharges GAB aquifers 
and how much is lost in surface and shallow subsurface processes, have been long-standing questions that need to be considered when modelling and managing GAB groundwater resources. Other important questions to consider relate to recharge time scales, spatial distribution, and how it is influenced by climate variability and change. The special issue provides an understanding of climate-change impacts on the GAB region, with a focus on spatio-temporal evolution of recharge, but also with valuable information for future water availability for water-resources planning. Two articles independently challenge traditional understanding of recharge processes by showing that most recharge remains in shallow zones and does not recharge the deep GAB aquifers, and offer methodologies applicable across the entire basin.

Discharge processes are equally complex and important. Several articles address this question, especially from the springs and associated GDEs perspective, enhancing understanding of discharge processes at springs, the role of structure in controlling discharge locations, and quantification of deep artesian waters versus locally-derived recharge in spring flow. These papers use a range of methods to quantify discharge, including remote sensing, hydrochemistry, isotopes, tree water-use quantification, fault-hydrogeology analysis and geophysics. A message from the special issue is (again) not only the growing dimensions, extent and resolution of relevant data and analytical innovations to accompany the data, but also the considerable important gaps that remain about spring sources and more broadly the GAB water balance.

Examples of effective participatory models for better management, including water-governance analyses, perception and acceptance of new technologies, and citizen science are given in the special issue. They show that communication, engagement and conflict management have improved with open data, citizen science and a broader acceptance of community and regulator collaboration. The paper addressing the social acceptance of enhanced water recovery is an apt example of the critical role of communication and engagement in facilitating sustainability innovations. Two articles proposed improved methodologies for estimating groundwater abstraction, highlighting uncertainties associated with the methods and data availability, and the need for targeted metering to better constrain estimations.

Despite these advances, there are still significant gaps in knowledge about the water balance of individual aquifers and the subbasins of the GAB, of the spatial and temporal variability in recharge and discharge processes, and how to use this knowledge to construct applicable communication and decision tools. The depth, scale and remoteness of the basin(s) present other challenges: metering of groundwater extraction is not mandatory; recording parameters that may be routine in other settings are complicated by aquifer depths in excess of $2 \mathrm{~km}$ and groundwater temperatures that can exceed $100{ }^{\circ} \mathrm{C}$; and field investigations typically require long-distance travel, and are time consuming and expensive. An additional challenge concerns the multiple stakeholder groups, agencies and states involved in the management and study of the GAB, and the communication issues that are related to such a variety of involved partners.

An opportunity for integration of many of the research outcomes in this special issue would be a GAB-wide conceptual and numerical model, extending the existing steady-state and transient GAB-wide numerical groundwater model by Welsh $(2000,2006)$ and as reviewed in Smith and Welsh (2011). Numerical models are often the operational face of hydrogeological research, through the use of knowledge, data and modelling methods in the modelling process. These research outcomes can be embedded in the GAB-wide conceptual and numerical model as new process or structural representations, or as new data sets to drive and calibrate the model, or be a knowledge base to direct the development and assessment of the underlying conceptual model. At the basin scale, a GAB-wide numerical model provides a useful synthesis of broad-scale hydraulic patterns. It can also provide the boundary conditions of targeted local models developed for decision support purposes or to support the exploration of finer-scale aquifer system responses. The model development, assessment and application can also be informed by visualisation tools and interact with stakeholder engagement practicesfor example, the OGIA numerical model of the Surat Cumulative Management Area over the past 7 years or so has integrated new data sets, new process knowledge and advances in numerical methods, and is part of a cyclic modelling and stakeholder engagement process associated with managing CSG impacts on groundwater (OGIA 2019). A comparable, enduring modelling project for the GAB could similarly encapsulate the advances in hydrogeologic understanding of the basin documented in this special issue and could serve as a resource to guide and integrate future advances.

Acknowledgements We pay respect to the Traditional Owners and their nations. We acknowledge the Traditional Owners have a deep cultural and spiritual connection to their lands and waters, and recognise the role of their inherent knowledge in progressing the science of the GAB.

We thank Helen Schultz for her insightful suggestions, Phil Hayes for his technical and strategic inputs and Suzi Moore for her coordination of the communications aspect of the project. We thank all authors for their contributions, especially those from nonresearch backgrounds, who made a remarkable effort to prepare their scientific manuscripts. We are grateful for the assistance and guidance provided by Hydrogeology Journal's executive editor Clifford Voss, editorial office manager Susanne Schemann and technical editorial advisor Sue Duncan.

Funding information The preparation of this special issue is part of the project "Resetting our understanding of the Great Artesian Basin", which is jointly funded by NERA (National Energy Resources Australia) and The University of Queensland Centre for Natural Gas (with its industry members Arrow Energy, Australia Pacific LNG and Santos). 


\section{References}

Ah Chee D (2002) Kwatye, indigenous peoples connection with kwatye (water) in the Great Artesian Basin. Environ S Aust 9:20-21

Business Queensland (2019) Interim Great Artesian Basin infrastructure investment program (IGABIIP). https://www.businessqldgovau/ industries/mining-energy-water/water/rural-assistance/igabiip. Accessed 7 December 2019

FAO (Food and Agriculture Organization of the United Nations) (2016) AQUASTAT: FAO's global information system on water and agriculture. http://www.fao.org/NR/WATER/AQUASTAT/countries regions/profile_segments/amazon-WR_eng.stm. Accessed 19 December 2019

Frontier Economics (2016) Economic output of groundwater dependent sectors in the Great Artesian Basin. A report commissioned by the Australian government and Great Artesian Basin jurisdictions based on advice from the Great Artesian Basin Coordinating Committee. Frontier Economics, London

Geoscience Australia (2018) Funding for Great Artesian Basin Groundwater Project announced in mid-year economic and fiscal outlook 2018-19. https://www.ga.gov.au/news-events/news/latestnews/funding-for-great-artesian-basin-groundwater-projectannounced-in-mid-year-economic-and-fiscal-outlook-2018-19. Accessed 7 November 2019

Geoscience Australia (2019) Navigating Australia's largest groundwater resource. http://www.ga.gov.au/news-events/features/navigatingaustralias-largest-groundwater-resource. Accessed 19 December 2019

Habermehl MA (1980) The Great Artesian Basin, Australia. BMR J Aust Geol Geophys 5:9-38

Habermehl MA (1982) Investigations of the geology and hydrology of the Great Artesian Basin, 1878-1980. Report 234 (BMR microfiche MF 169), Bureau of Mineral Resources, Geology and Geophysics, Canberra, Australia

Habermehl MA (2001) Hydrogeology and environmental geology of the Great Artesian Basin, Australia. In: Gostin VA (ed) Gondwana to greenhouse: Australian environmental geoscience. Geol Soc Aust Spec Publ 21:127-346

Hillier JR, Foster L (2002) The Great Artesian Basin - is there a sustainable yield? International Association of Hydrogeologists conference, Darwin, 2002. Abstacts with program
Keppel MN, Karlstrom KE, Love AJ, Priestley S, Fulton S, Wohling D, De Ritter S (eds) (2013) Allocating water and maintaining springs in the Great Artesian Basin, vol I: hydrogeological framework of the western Great Artesian Basin. National Water Commission, Canberra

Moggridge BJ, Lyndal Betterridge L, Thompson RM (2019) Integrating aboriginal cultural values into water planning: a case study from New South Wales, Australia. Aust J Environ Manag. https://doi. org/10.1080/14486563.2019.1650837

OGIA (Office of Groundwater Impact Assessment) (2019) Underground water impact report for the Surat Cumulative Management Area. Consultation draft May 2019. https://www.dnrme.qld.gov.au/data/ assets/pdf_file/0010/1445554/uwir-2019-report.pdf. Accessed 17 July 2019

Ostrom E (1990) Governing the commons: the evolution of institutions for collective action. Cambridge University Press, Cambridge

Radke BM, Ferguson J, Cresswell RG, Ransley TR, Habermehl MA (2000) Hydrochemistry and implied hydrodynamics of the Cadnaowie-Hooray aquifer, Great Artesian Basin, Australia. Bureau of Rural Sciences, Canberra, 229 pp

Ransley TR, Radke BM, Feitz AJ, Kellett JR, Owens R, Bell J, Stewart G, Carey H (2015) Hydrogeological atlas of the Great Artesian Basin. Geoscience Australia, Canberra. https://doi.org/10.11636/ 9781925124668

Smerdon BD, Ransley TR, Radke BM, Kellett JR (2012) Water resource assessment for the Great Artesian Basin. A report to the Australian Government from the CSIRO Great Artesian Basin Water Resource Assessment, CSIRO Water for a Healthy Country Flagship, Canberra

Smith AJ, Welsh WD (2011) Review of groundwater models and modelling methodologies for the Great Artesian Basin. A technical report to the Australian Government from the CSIRO Great Artesian Basin Water Resource Assessment, CSIRO Water for a Healthy Country Flagship, Canberra

White DC, Lewis MM (2011) A new approach to monitoring spatial distribution and dynamics of wetlands and associated flows of Australian Great Artesian Basin springs using QuickBird satellite imagery. J Hydrol 408:140-152

Welsh WD (2000) GABFLOW: a steady state groundwater flow model of the Great Artesian Basin. Bureau of Rural Sciences, Canberra

Welsh WD (2006) Great Artesian Basin transient groundwater model. Bureau of Rural Sciences, Canberra 